\title{
Large scale testing of surface support
}

\author{
R. Brändle1, R. L. Fonseca ${ }^{2}$, and T. Hangartner ${ }^{1}$ \\ ${ }^{1}$ Geobrugg AG, Switzerland \\ ${ }^{2}$ Geobrugg Ibérica S.A., Spain
}

\begin{abstract}
Ground support for dynamic conditions must be able to withstand the associated loads and deformations and the support scheme must work as a system. In order to prove the suitability of such support systems with high-tensile steel mesh and bolts, and also to analyse their bearing behaviour, a large-scale test setup was commissioned in Walenstadt, Switzerland. On this test rig, it was possible to apply large energies on variable ground support schemes with variable bolt patterns and meshes with a total support area of $3.6 \mathrm{~m}$ $x 3.6 \mathrm{~m}$. The test site is instrumented by load cells, high-speed video analysis and accelerometers. In this paper the analysis of the load cells, the accelerometers and the highspeed video cameras is given, and results are discussed. It could be shown that a combination of high-tensile steel mesh with a specific bolt pattern can result in high energy capacity surface support. Distribution of the impact loads during the stoping process to the different elements of the bearing support system depends on the strength and flexibility of the mesh and the bolts resistance and his pattern.
\end{abstract}

\section{INTRODUCTION}

Mining is getting deeper, and rockburst damage is a growing risk in underground excavations around the world. In mining tunnels in particular, when in search of the mineral strata, tunnels are deepened more and more, until reaching depths greater than 1,000 m. However, seismic events and associated rockburst can occur even at lower depths.

Requests to increase the energy dissipation capacity in the support system designs in mines, is a frequent one. With this in mind, systematic studies have been carried out to improve the performance of the individual elements as well as the reinforcement systems as a whole.

In addition, the development of diamond-shaped lightweight steel wire membranes of very hightensile strength, in recent years, has led to a significant reduction to this trend. These powerful, flexible solutions combined with suitable anchors, have undoubtedly been a huge step forward in provide ng solutions where protection against dynamic load is imperative.

\section{HIGH-TENSILE STRENGTH STEEL WIRE MEMBRANES}

The high-tensile wire (1,770 MPa) mesh offers a surface support for many different ground conditions. The mesh is manufactured from high-tensile steel wire with a diameter of between $4 \mathrm{~mm}$ and/or $3 \mathrm{~mm}$. The mesh has a specifically developed, diamond shape to minimise deformations; and along the edges, each spiral wire is looped and twisted back on itself. This enables the edge of the mesh to have the same loading capacity as the mesh Luis Fonseca, R. et al (2009). In terms of corrosion protection, the wire is coated with a special aluminium-zinc coating, which has a higher corrosion resistance than standard zinc galvanising. 
The resistance properties of the mesh were determined in a series of laboratory tests (2002) at the University of Cantabria, Spain. The properties of the meshes are summarized in Table I.

Table I. Properties of the high-tensile mesh

\begin{tabular}{|c|c|c|}
\hline Material & G65/4 & G80/4 \\
\hline mesh width & $63 \mathrm{~mm}$ & $80 \mathrm{~mm}$ \\
diagonal & $83 \times 138 \mathrm{~mm}$ & $102 \times 177 \mathrm{~mm}$ \\
wire diameter & $4 \mathrm{~mm}$ & $4 \mathrm{~mm}$ \\
wire strength & $1,770 \mathrm{MPa}$ & $1,770 \mathrm{MPa}$ \\
breaking load of wire & $22 \mathrm{kN}$. & $22 \mathrm{kN}$. \\
tensile strength & $250 \mathrm{kN} . / \mathrm{m}$ & $190 \mathrm{kN} . / \mathrm{m}$ \\
weight & $3.3 \mathrm{~kg} / \mathrm{m}^{2}$ & $2.6 \mathrm{~kg} / \mathrm{m}^{2}$ \\
\hline
\end{tabular}

\section{Dynamic laboratory tests}

The G80/4 mesh was tested at the dynamic testing facility of the Western Australian School of Mines (WASM), Player et al (2008), by using a momentum transfer method, Player et al (2004); Thompson et al (2004). The mesh panel is installed using shackles and eye-bolts in the frame and the weight is placed on top of the mesh. The full system is dropped onto buffers from different heights. When the system hits the buffers, everything comes to a sudden stop, except the weight placed on the mesh that keeps decelerating and loads the mesh dynamically. This simulates a situation where the mesh is placed against the rock mass, and can eject into the surface support (mesh) under dynamic load. The dynamic test apparatus is instrumented with a high-speed video camera, load cells and accelerometers. Figure 1 shows a general view of the test setup at the WASM facility, Roth (2013).

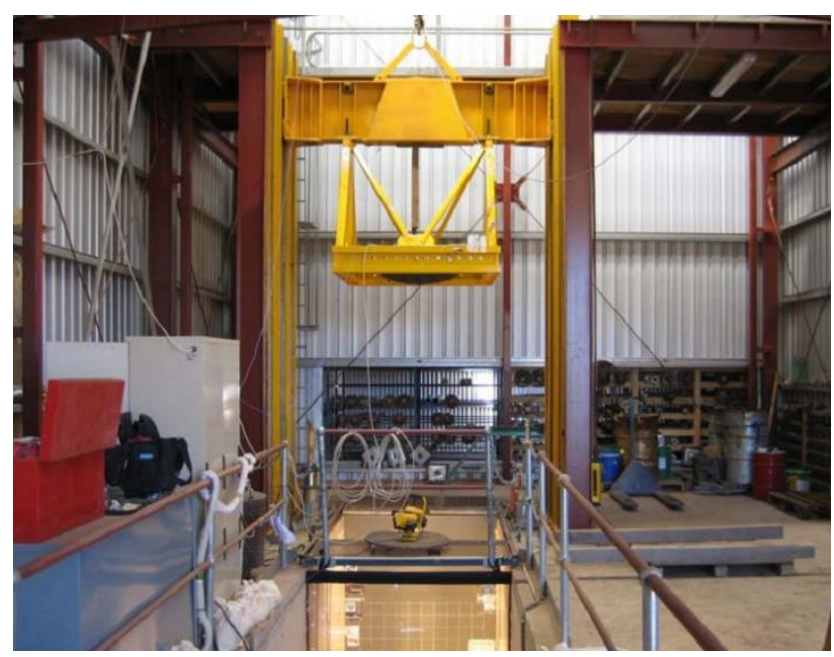

Figure 1. Dynamic test setup, WASM, Kalgoorlie, Roth (2013)

In Figure 2, images from a camera (Figure 2a) and a high-speed video camera (Figure $2 b$ ) are shown before and after a mass of $1,000 \mathrm{~kg}$ (bag with mill steel balls) hits the high-tensile chain link mesh. The mesh deforms with the applied load and transfers the forces to the boundary. The boundary conditions are fixed to have comparable and repeatable results. 


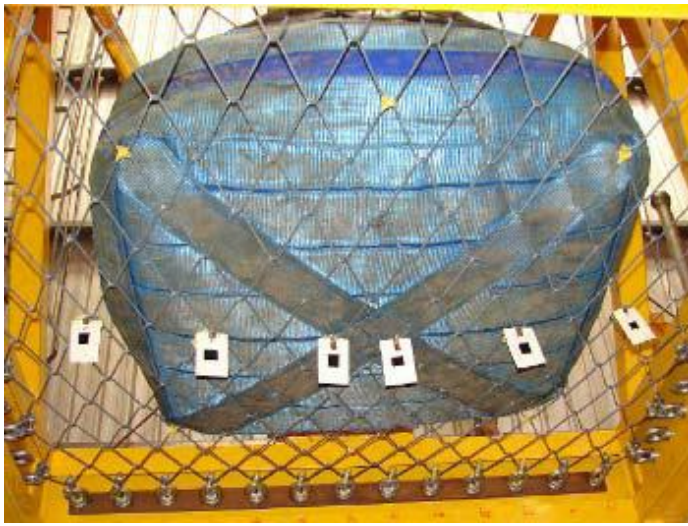

(a)

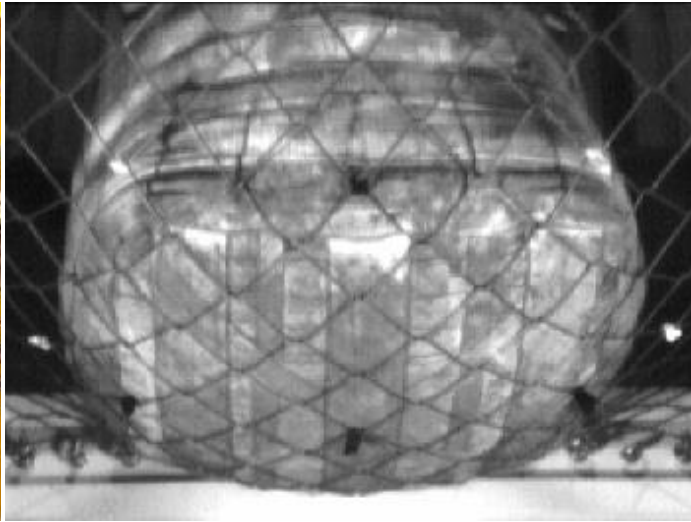

(b)

Figure 2. Photo (a) - from underneath the test arrangement before the $1000 \mathrm{~kg}$ impact mass; and Photo (b): from the high-speed video camera after impact-Villaescusa et al (2012)

It was established that the high-tensile chain link mesh G80/4 is able to absorb energies of up to $12 \mathrm{~kJ}$ in such a configuration, Villaescusa et al (2012). This is equal to stopping a rock mass of $1,000 \mathrm{~kg}$ accelerated to $4.9 \mathrm{~m} / \mathrm{s}$. This value represents the energy absorption of the mesh only and does not include any absorption by the rock mass or the yielding bolts.

In order to determine the distribution of loads between the anchor bolts and the surface support, tests were carried out at the Geobrugg facility in Switzerland, Bucher et al (2013). These tests found that the distribution between bolts depends on the rigidity of the rock mass. That is, for a rigid rock mass, $25 \%$ of the dynamic energy entering the system is absorbed by the mesh, with the remaining $75 \%$ being absorbed by the bolts. With a soft rocky mass, the distribution is $70 / 30$ respectively, as both cases represent extreme conditions.

\section{ROCKBURST LARGE-SCALE TEST}

The large-scale testing was the main part of a research and development project supported by Codelco. A series of large-scale tests were conducted during September 2016 in a quarry in Walenstadt (rockfall testing facility) Switzerland, and described in a Dynamic Test Center AG (DTC) test report (See Saner, A., and Murri, R. (2016)). The chief goals for performing large-scale tests were: increasing knowledge about the behaviour and the interaction of ground and the anchored flexible support in front dynamic load, and checking the reliability and validation of the dimensioning assumptions based on test site observations and back calculations. Initial experiments of the test programme allowed for observation and optimization of the test setup, testing procedure and data acquisition method. After optimization of the test setup, the following experiments were repeatedly conducted to guarantee reliable and comparable results.

The dynamic load is reproduced by dropping a barrel filled with steel and concrete. The impact site of the barrel was in the middle of the simulated ground support layer. The accelerations in the three main axes were measured on the top of the barrel. In addition, the forces acting during the test on the anchors were detected by measurement equipment. The test was recorded with two high-speed and two realtime cameras. The deflection was determined with a side-mounted high-speed camera.

\section{Test arrangement}

The test device is composed of a platform with two-levels of square-shaped pyramidal trunk geometries (See Figure 3a). In the upper level housing, the impact set consists of a 1,320 kg barrel dropped from a height of $4.6 \mathrm{~m}$ for test S3 and S5, and from $2.3 \mathrm{~m}$ for test $\mathrm{S} 4$. The barrel is guided with 4 steel profiles. The lower level is composed of a shotcrete slab, together with the mesh layers fixed by anchors, which 
are attached to the upper level. The impact area surface was increased to $1 \mathrm{~m}^{2}$ by a steel plate (See Figure $3 b)$. A copper contact was mounted on the steel plate to determine the moment of first contact.

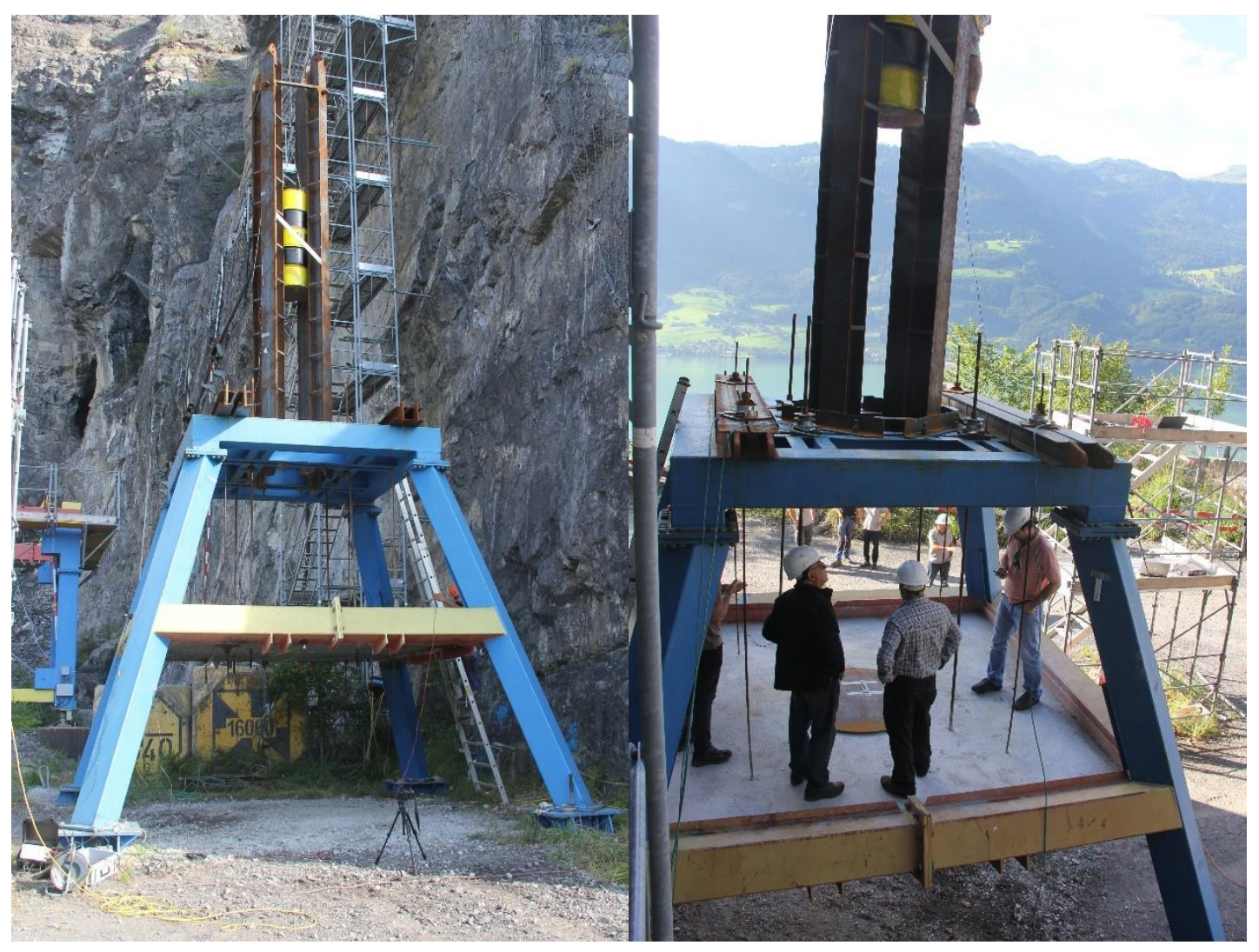

(a)

(b)

Figure 3. Photo (a) - Frontal view of the full setup; and (b) test frame with people for scale

The dimensions of the first level slab are 3.6x $3.6 \mathrm{~m}$ (See Figure 4). Two different types of anchors are used in different patterns; the external composed of cable bolts of $140 \mathrm{~mm}^{2}$ arranged in a grid of $2.0 \mathrm{x}$ $2.0 \mathrm{~m}$ and the inner, consisting of a pattern $1.2 \times 1.2 \mathrm{~m}$ of diameter $\varnothing 25 \mathrm{~mm}$ rock bolt anchors. 


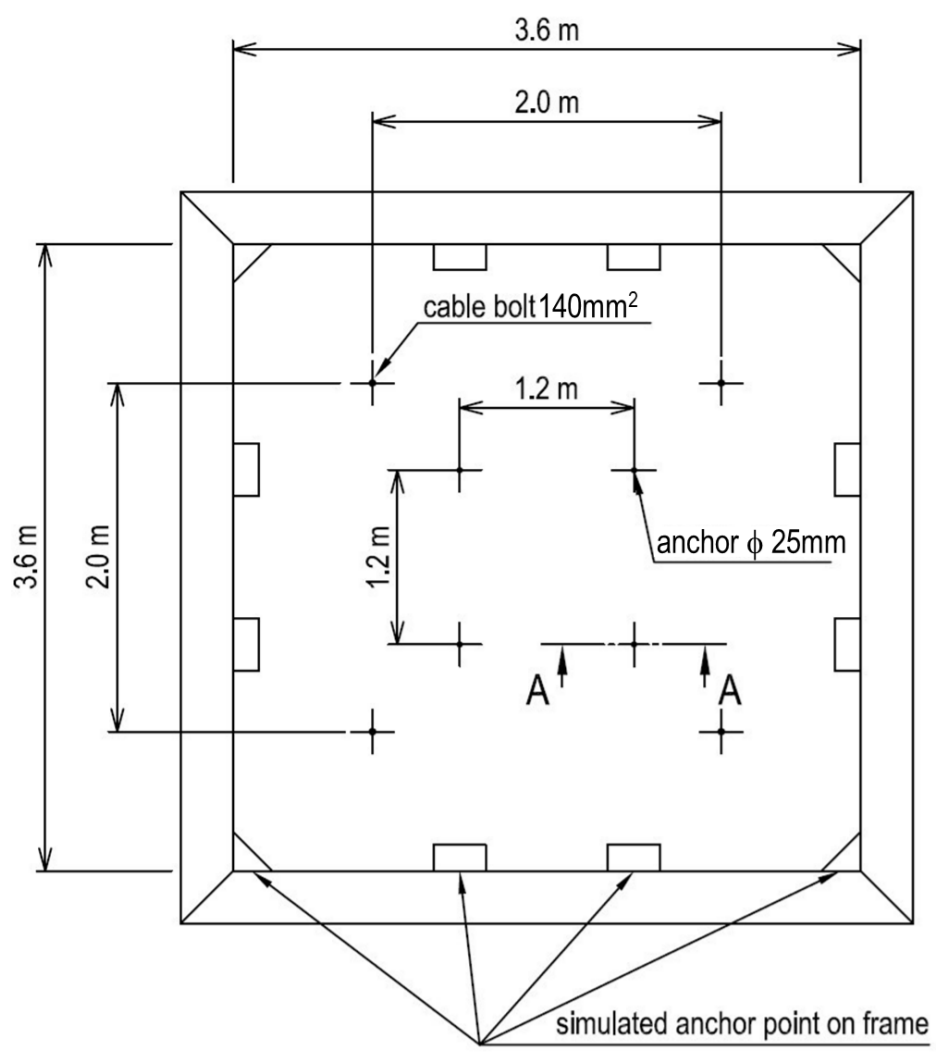

Figure 4. level frame, top view with the shotcrete slab and the anchoring points

The previously described shotcrete slab is composed of two layers. The upper one is $\sim 70 \mathrm{~mm}$ thick and consists of shotcrete, immediately underneath is placed a layer of high strength mesh type G65/4. The lower shotcrete layer is thinner (about $30 \mathrm{~mm}$ ) and below is placed the second mesh layer type G80/4 (See the set details in Figure 5).

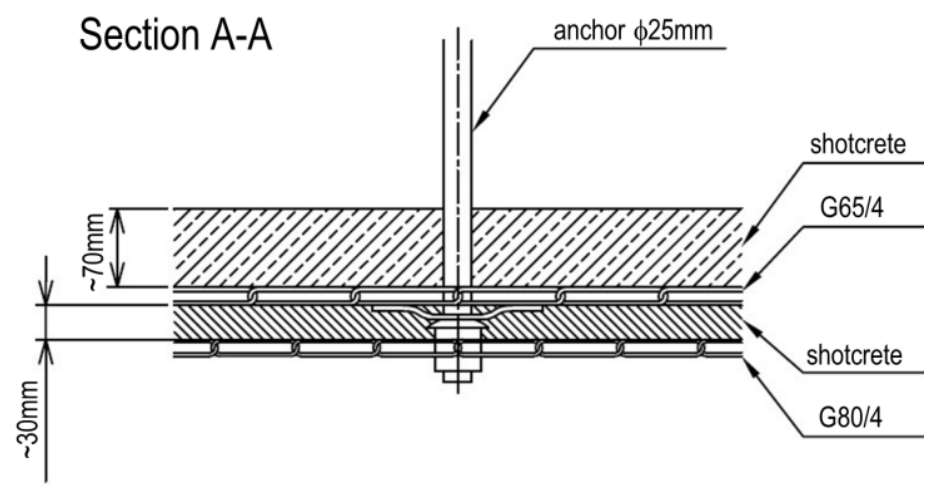

Figure 5. Set cross section A-A: composed of two layers of shotcrete and two of high tensile strength mesh

\section{Measurement and data recording}

The accelerations of the barrel were measured in the middle of the top surface using a three-axis accelerometer $(2000 \mathrm{~g})$. The forces were measured with four load cells at four anchors. Due to the symmetrical design, the measured forces were multiplied by two for the resultant force on all eight anchors. Measurement channels 1, 2, 3 and 4 correspond to anchors (See Figure 6). 


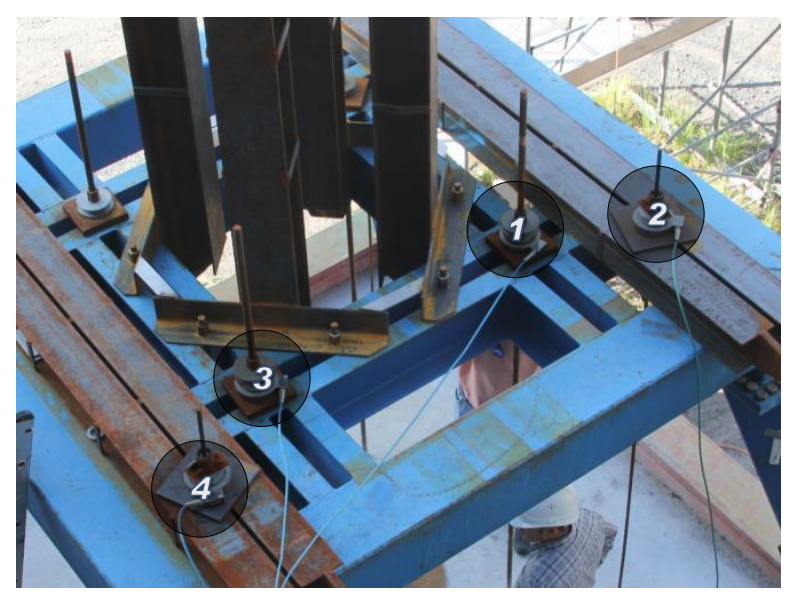

Figure 6. Measuring equipment on top of the barrel and (b) Load measurement cells

The coordinates system origin (zero-point) is in the middle of the shotcrete floor where the barrel hits the metal plate on the shotcrete slab floor: $+X$ (positive right) $+Y$ (positive back) and $+Z$ (positive upwards). (See Figure 7).

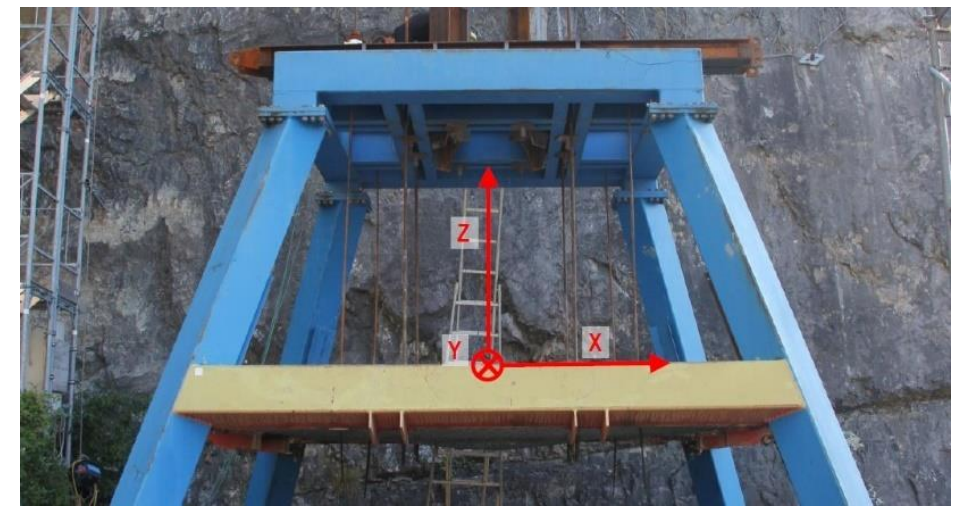

Figure 7. Test field coordinates system

Two stationary digital high-speed and two real-time cameras were used for the visual documentation of the test and to determine the deflection. The cameras were manually triggered and synchronized by LEDs. For the frontal camera, it uses the high-speed cameras AOS technologies, type X-EMA (Extended Environmental Application) which is a camera that can be used under the toughest conditions (See Figure 8a). 


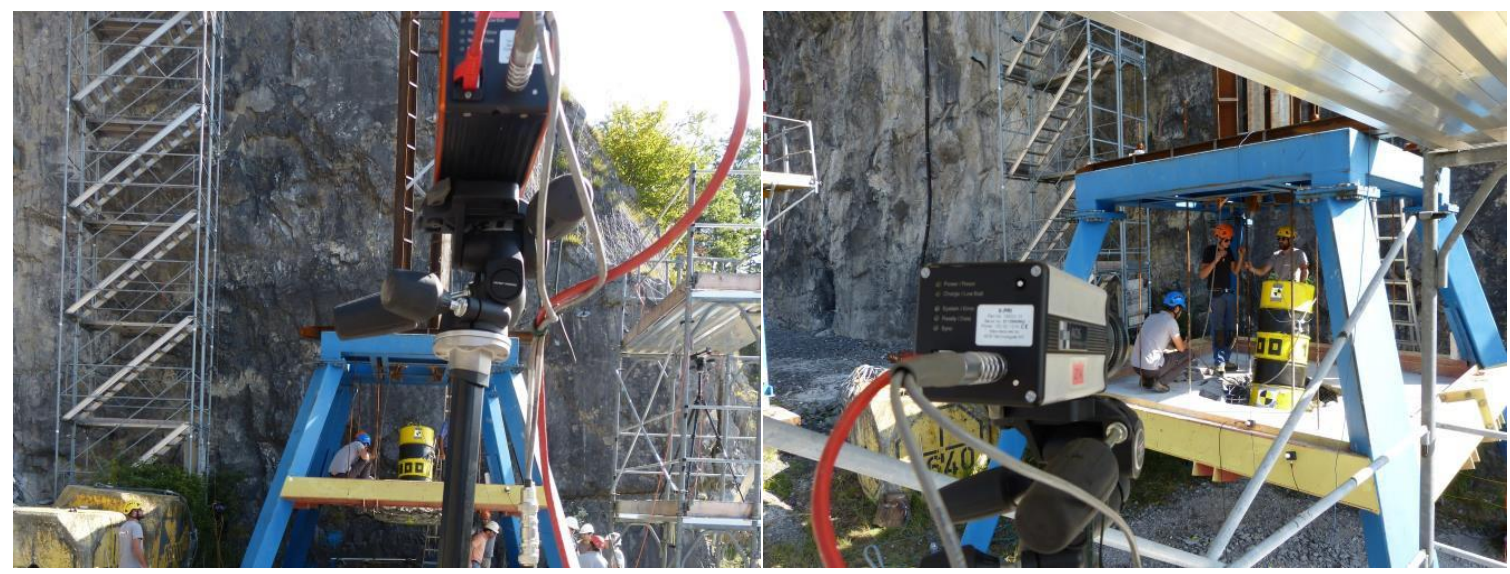

(a)

(b)

Figure 8. (a) Camera AOS X-EMA focal distance $25 \mathrm{~mm}$ and (b) Camera AOS X-Pri focal distance $50 \mathrm{~mm}$

\section{Test results and video analysis}

On September 28, 2016, three trials were undertaken, S3, S4 and S5. In all tests, the same barrel was used in the same impact area $\left(1 \mathrm{~m}^{2}\right)$, while the release height was varied from $4.60 \mathrm{~m}$ (S3-S5) to $2.30 \mathrm{~m}$ in the S4 test, which halved the energy in the contact moment. A sequence of frames is shown in Figure 9, taken during the first tests (S3). In this sequence, it was possible to see the effect of the impact of the barrel on the distribution plate of $1 \mathrm{~m}^{2}$ on the shotcrete slab and the rebound effect manifested when it reached the maximum deflection at $\mathrm{t}=100 \mathrm{~m} / \mathrm{s}$.

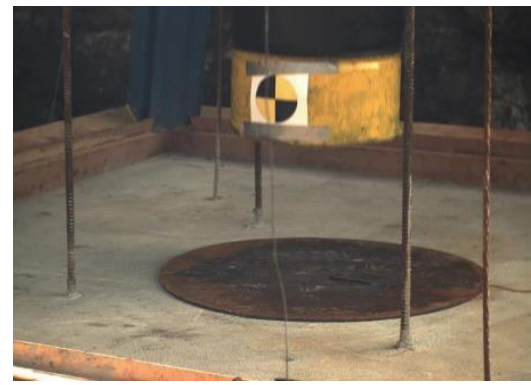

$t=-50 \mathrm{~ms}$

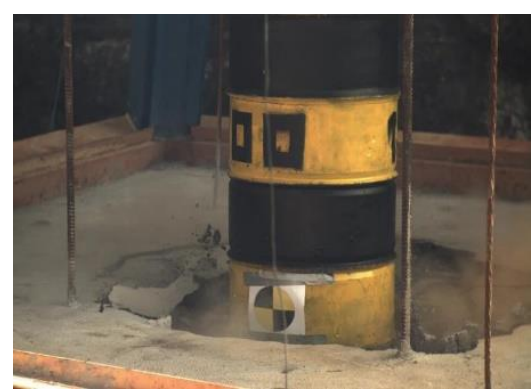

$t=100 \mathrm{~ms}$

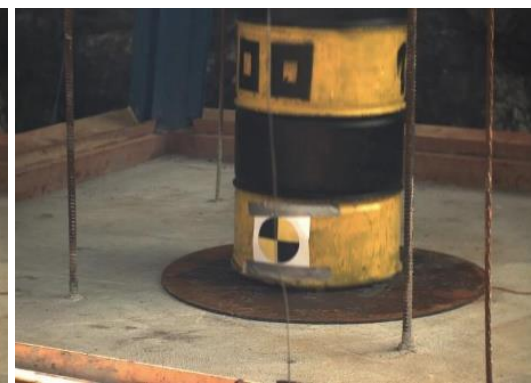

$t=0 \mathrm{~ms}$

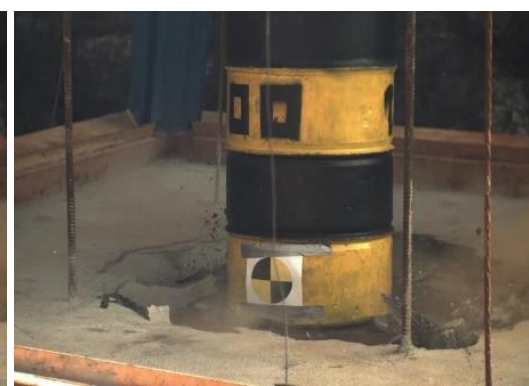

$t=150 \mathrm{~ms}$

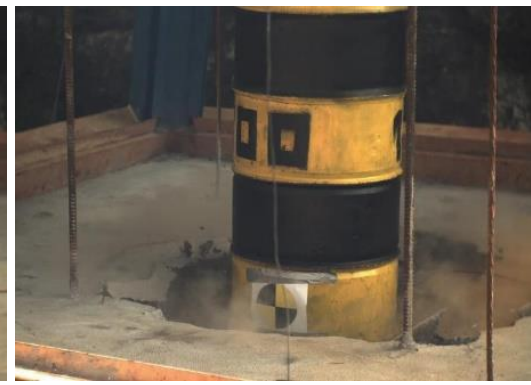

$t=50 \mathrm{~ms}$

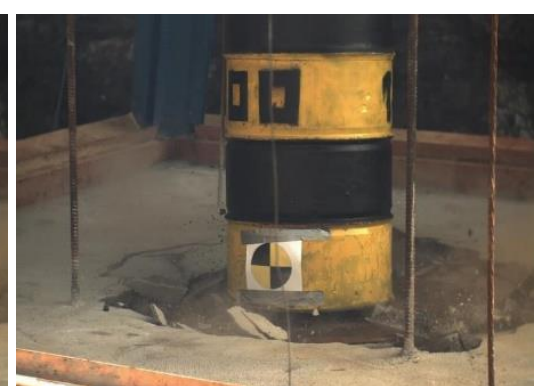

$t=200 \mathrm{~ms}$

Figure 9. Impact sequence during test S3

The S3 test results show the release height at $4.60 \mathrm{~m}$, with the barrel weighing $1320 \mathrm{~kg}$; it was then 
dropped onto the shotcrete slab at a speed of $9.5 \mathrm{~m} / \mathrm{s}(34.2 \mathrm{~km} / \mathrm{h})$, corresponding to impact energy of $60 \mathrm{~kJ}$ (See Figure 10); in this case, the total amount of the force into the anchoring system is $429 \mathrm{kN}$, and the maximum acceleration achieved is $70.5 \mathrm{~g}$ (See Figure 11). The barrel was completely restrained by the rockburst setup, with a deflection of $0.24 \mathrm{~m}$, whose residual static value is slightly lower at $0.225 \mathrm{~m}$ (See Figure 12 and 13).

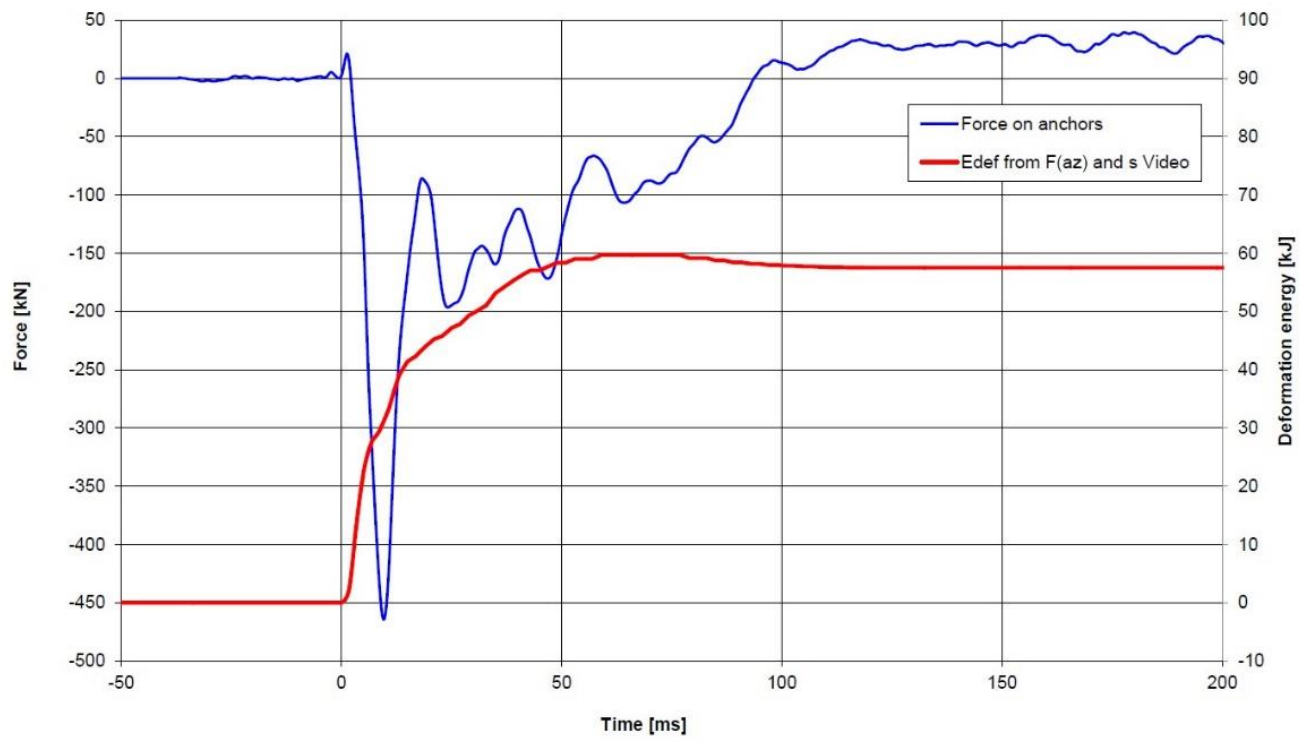

Figure 10. Test results of test S3. Sum of the forces (blue) in the load cell for anchors multiplied by two (extrapolation from 2 measured anchors to the 4 anchors used) and maximum energy (red) recorded

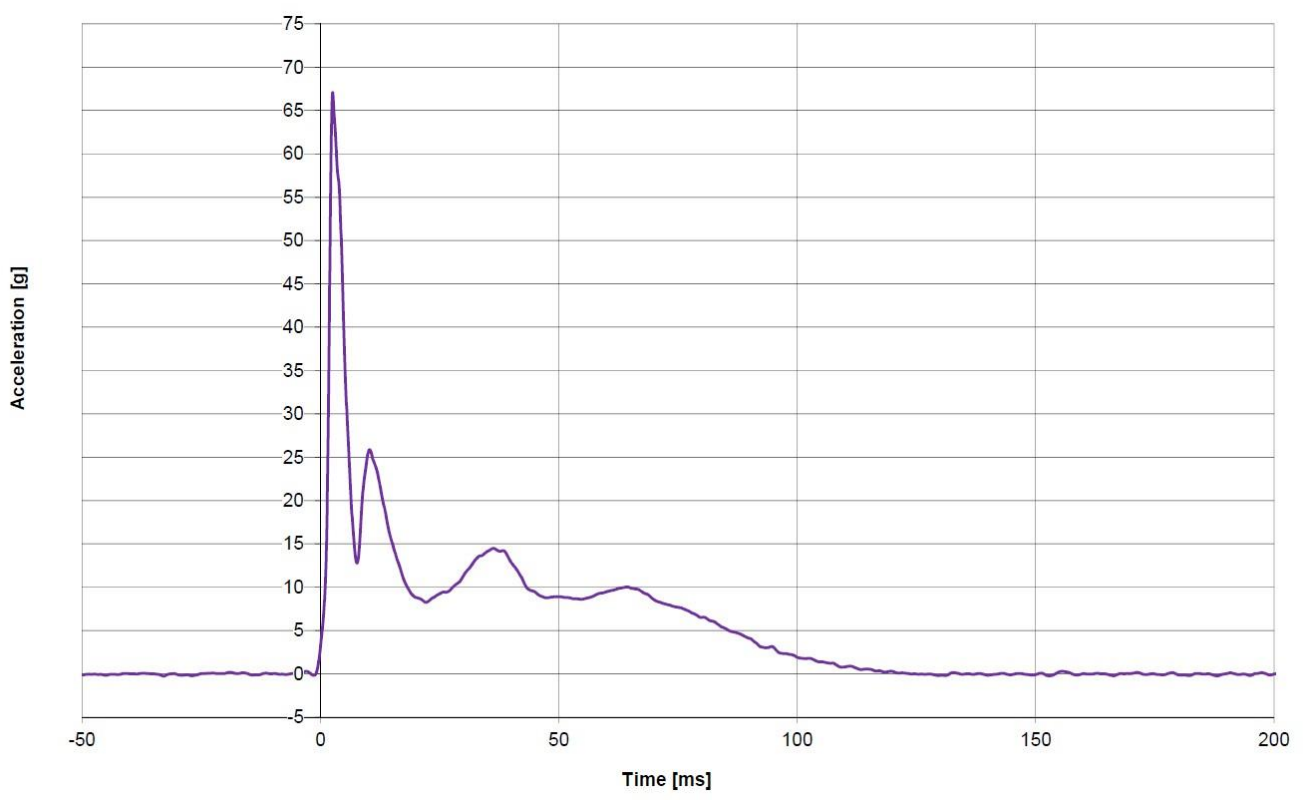

Figure 11. Test results of test S3. Acceleration on barrel at $Z$ direction (filter CFC 180) 


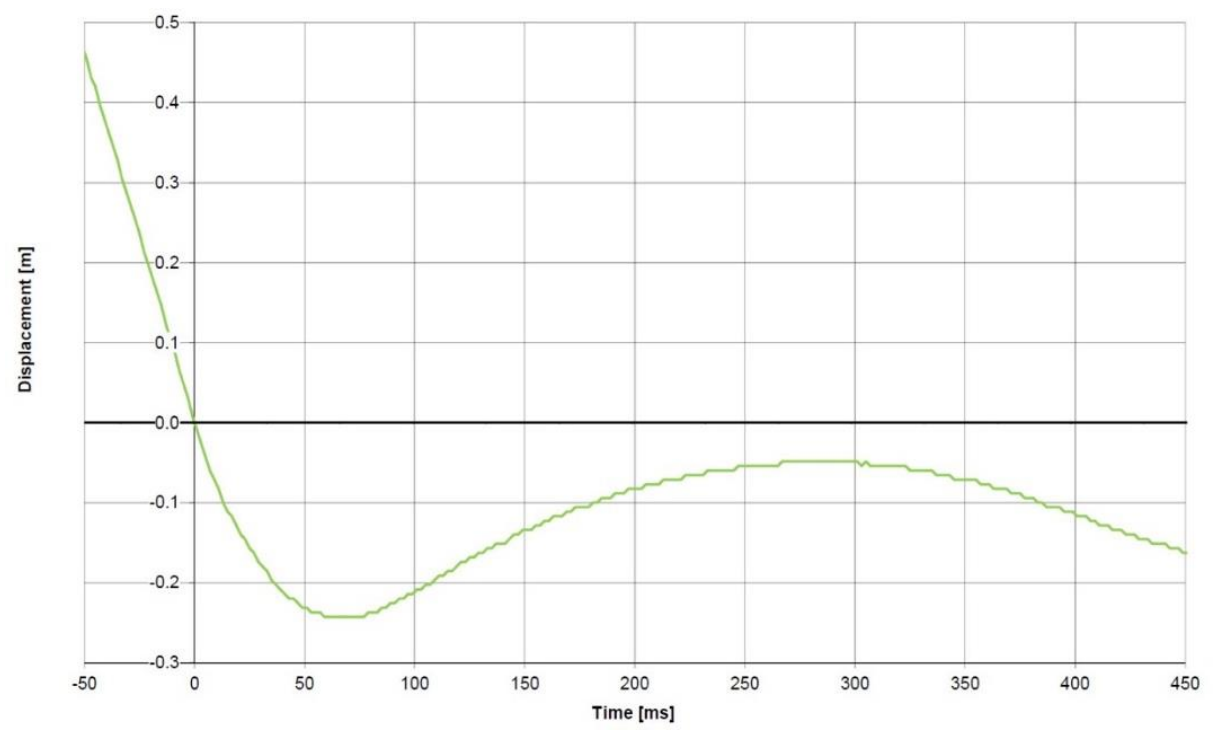

Figure 12. Test results of test S3. Maximum displacement $(0,24 \mathrm{~m})$

Figure 13 shows the consequences of the impact on the strong support system, the effect of the fast load, seen from above and below, where the protection level remains right. The residual deformation is very small and the level of high energy absorption up to $60 \mathrm{~kJ}$.

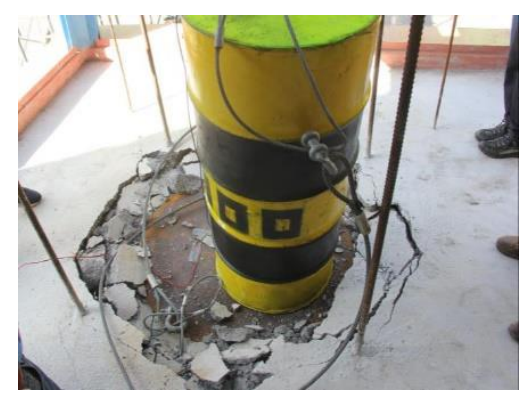

Impact point after test, top view

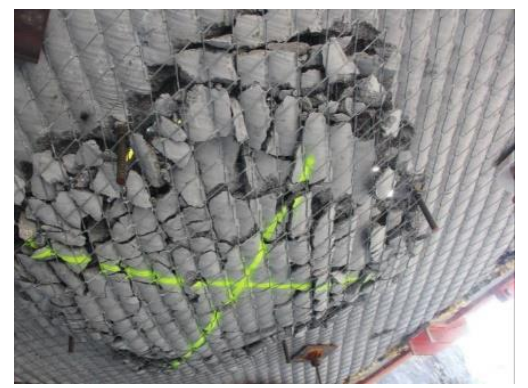

Impact point, bottom view

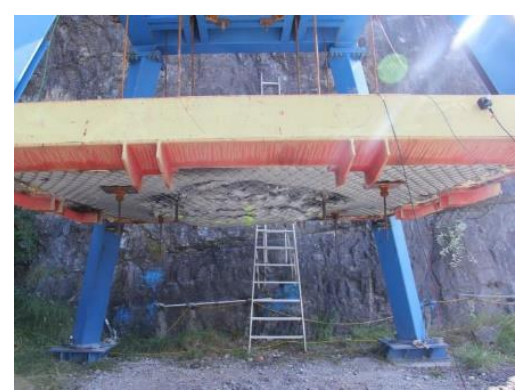

Frontal view of slab, bottom view

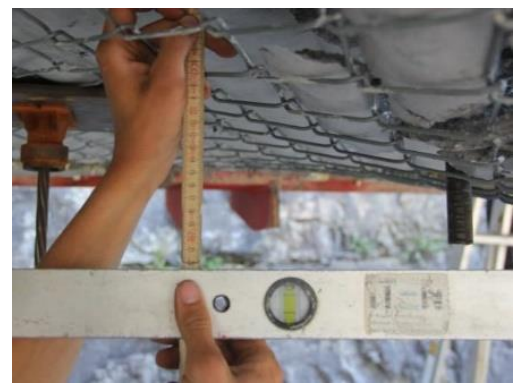

Remaining elongation of $0.225 \mathrm{~m}$ after impact

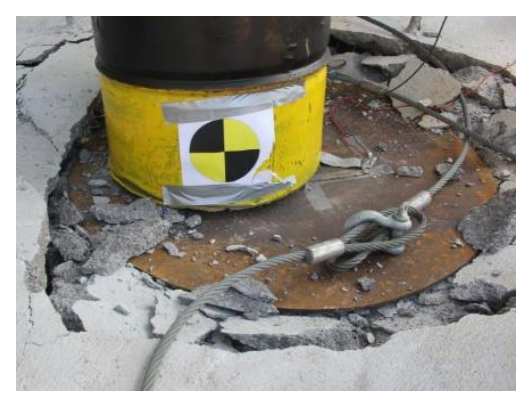

Steel plate not deformed, top view

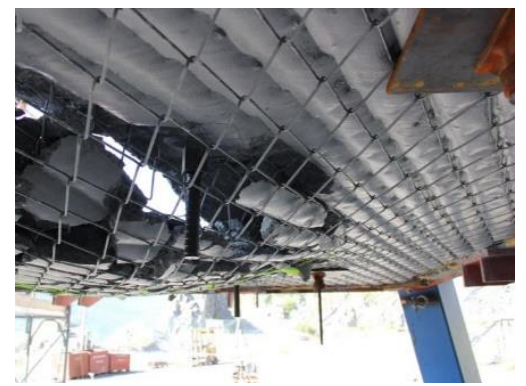

Detail of lower mesh G80/4

Figure 13. Final setup statuses after the first test, S3

Once the S3 test was completed, the second impact (S4) was prepared on the same surface which was previously affected by the S3 test impact so that the behaviour of the ground support solution can be evaluated over an area affected by more than one consecutive event, but without prior repair. A sequence of frames is shown below (See Figure 14) during the second test (S4). 


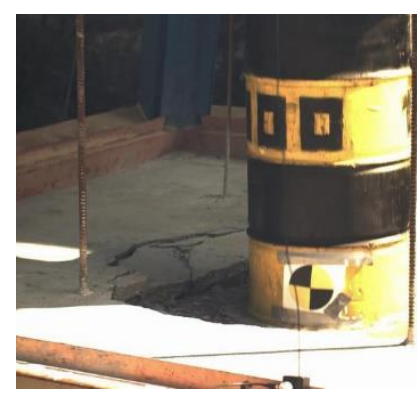

$t=-0 m s$

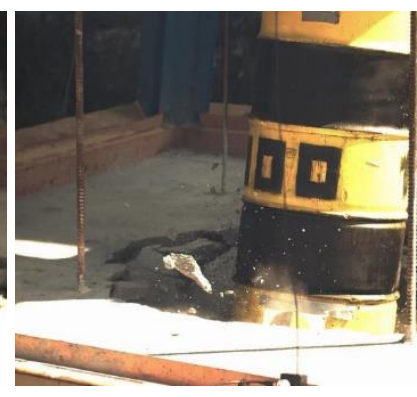

$t=100 \mathrm{~ms}$
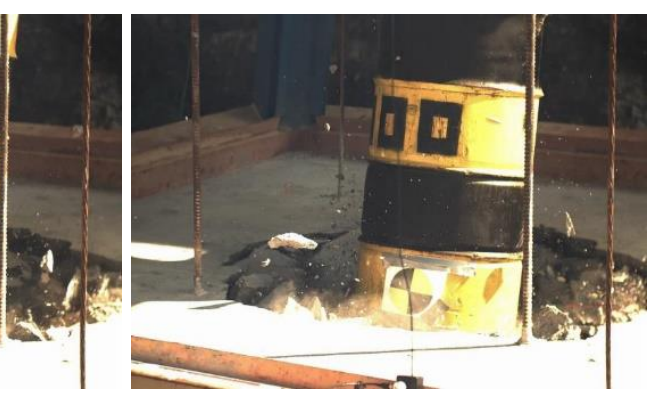

$t=200 \mathrm{~ms}$

Figure 14. Impact sequence during test $S 4$

The $\mathrm{S} 4$ test results are as follows: The release height is half that of the previous $2.30 \mathrm{~m}$, and the barrel weight is the same so therefore the impact energy is about $30 \mathrm{~kJ}$. This test show that the system can absorb $30 \mathrm{~kJ}$ as a second impact (previously impacted with $60 \mathrm{~kJ}$ ). In this case, the total amount of the forces into the anchoring system is $162 \mathrm{kN}$, and the maximum acceleration achieved is $33.4 \mathrm{~g}$ while the elongation is $\sim 0.20 \mathrm{~m}$ (Figure 15).

The results of the impact over a strong support system are shown in Figure 15. The effects of the load applied at high speed, seen from above and below, show that the residual deformations are very small and the energy absorption is up to $30 \mathrm{~kJ}$.

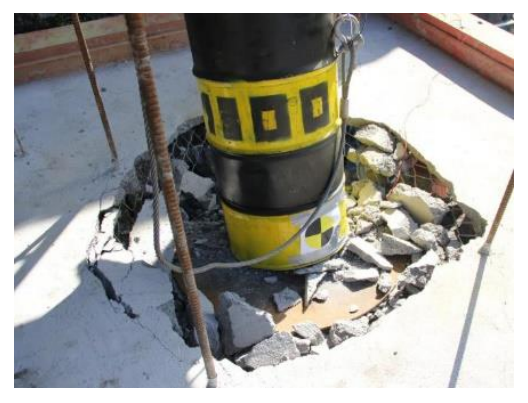

Impact point after test, top view

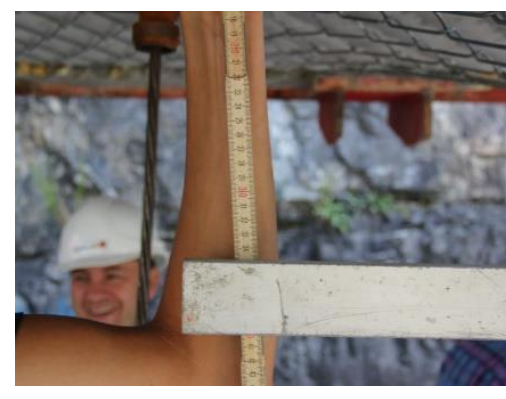

Remaining elongation of $0.345 \mathrm{~m}$ after impact

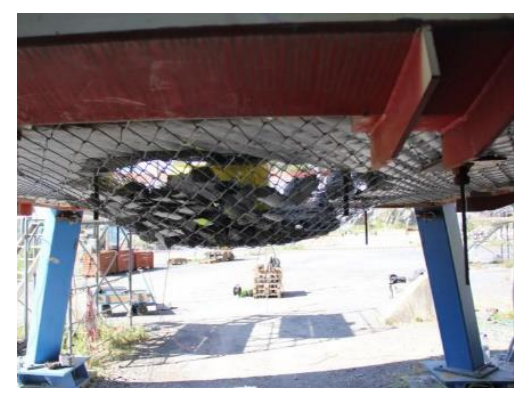

Impact point. Bottom view

Figure 15. Final setup statuses after the second test S4

The S5 (Last tests performed, see Figure 16), was carried out on the previously tested support system on which test S3 and test S4 were done. Tests were conducted without any maintenance work on the steel membranes or the anchoring system, while the shotcrete layer present at the beginning, is already gone. All the support forces were transmitted to the anchoring system by the two layers of high tensile wire mesh $4 \mathrm{~mm}$ diameter with openings of $65 \mathrm{~mm}-80 \mathrm{~mm}$ respectively. 


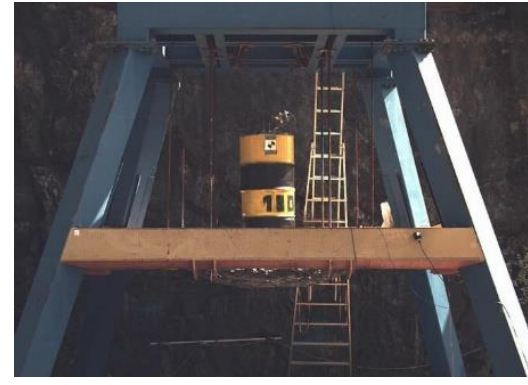

$t=0 \mathrm{~ms}$

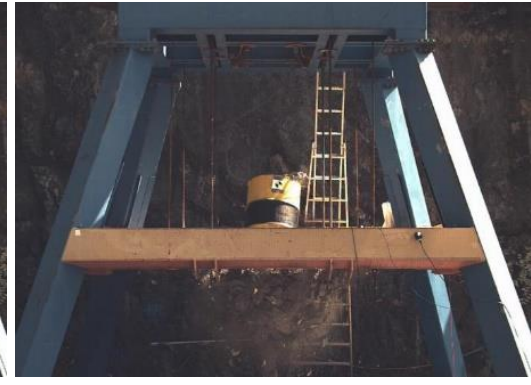

$t=100 \mathrm{~ms}$

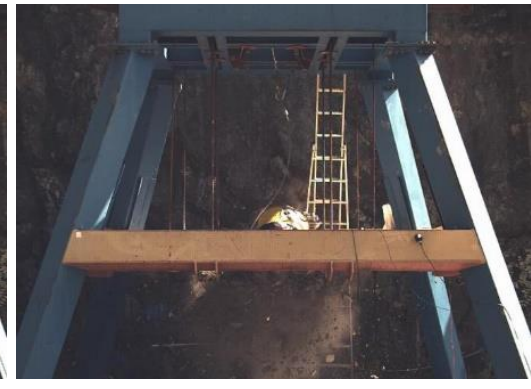

$t=200 \mathrm{~ms}$

Figure 16. Impact sequence during test S5

The S5 test results of a drop with a release height of again $4.60 \mathrm{~m}$ and barrel weight of $1,320 \mathrm{~kg}$, returned impact energy of $\sim 60 \mathrm{~kJ}$. This test shows that the system can absorb $60 \mathrm{~kJ}$ as a third impact (previously impacted with $60 \mathrm{~kJ}$ and $30 \mathrm{~kJ}$ ), and in this case the total amount of the forces into the anchoring system is $155 \mathrm{kN}$. The maximum acceleration achieved is $32.5 \mathrm{~g}$ and the elongation is $\sim 0.60 \mathrm{~m}$.

\section{Support system safety factor}

According to the forces measurements in test S3, the maximum force values are generated in the anchors 1 and 3 (See Figure17) These points correspond to the inner anchors system composed of steel bars of $\varnothing 25 \mathrm{~mm}$. As can be seen, the maximum values observed in the test are in the order of $125 \mathrm{kN}$; when anchor bars of $\varnothing 25 \mathrm{~mm}$ are used, there is a yield strength force of $241 \mathrm{kN}$, and the safety factor of the system anchors is 2 .

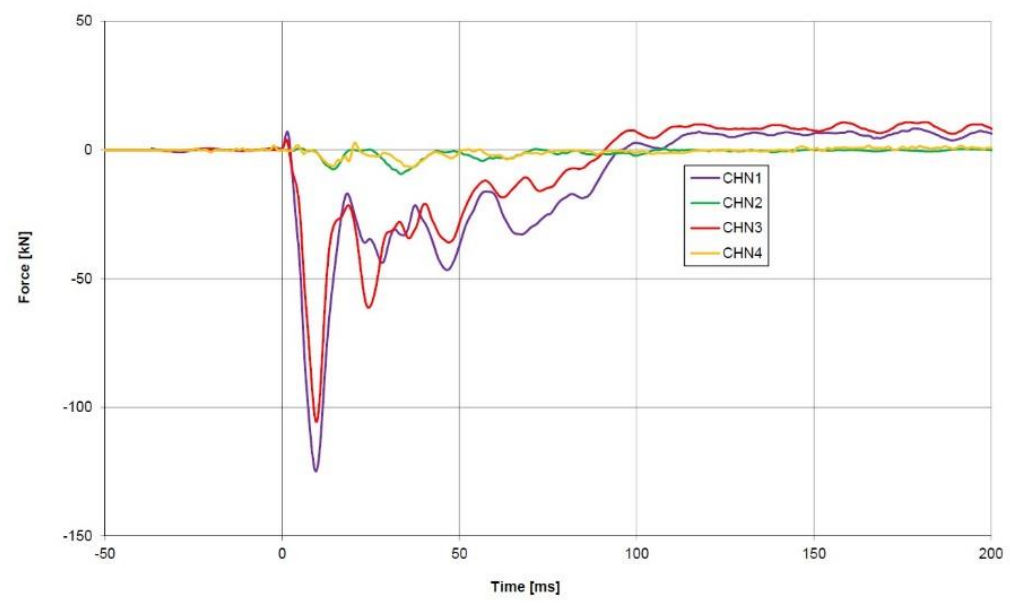

Figure 17. Test results of test S3. Anchor forces in Z direction (filter CFC 180)

\section{CONCLUSIONS}

These large-scale tests attempted to simulate the conditions of a mine, edge conditions are generated, (for example, free anchors without grout), which cannot return a perfect correlation between the results obtained in the test with the results expected at the mine. However, it allows comparisons between systems / elements of fortification and helps to advance understanding the complex problems associated with rockburst.

To this successful test of a reinforcement system (using shotcrete with mesh, rock bolt and a second mesh with cable bolts) under dynamic conditions, one can add experimental antecedents to the theory and confirm that this type of support might be beneficial in potential rock burst areas. 
Dynamic laboratory tests have also contributed to the primary knowledge and established initial parameters of comparison between different elements; however, the need to work on a small scale, limits the possibilities required for a perfect simulation of reality and it is therefore important to understand how the test was carried out and the significant of the results.

The elements of the measurement system (load sensors, accelerometers and high-speed video cameras) showed their suitability in obtaining data. The detailed description of each test also gives data related with acceleration and displacement of the system after impact.

\section{REFERENCES}

Bucher, R., Cala, M., Zimmermann, A., Balg, C. and Roth, A. (2013). Large scale field tests of high-tensile steel wire mesh in combination with dynamic rock bolts subjected to rock burst loading, 7th International Symposium on Ground Support in Mining and Underground Construction, Perth, 13-15 May

Luis Fonseca, R., Laguna L., and Muñoz, B. (2009). Comparative analysis of the mechanical properties of the steel membranes for slope stabilization, VII National Symposium on Unstable Hills and Slopes. Barcelona. Spain.

Player, J., Villaescusa, E. and Thompson, A. (2004). Dynamic testing of rock reinforcement using the momentum transfer concept, Ground Support Symposium, Perth, Australia, pp. 327-339.

Player J., Morton E., Thompson A. \& Villaescusa E. (2008). Static and dynamic testing of steel wire mesh for mining applications of rock surface support, The Sixth International Symposium on Ground Support in Mining and Civil Engineering Construction, Cape Town, South Africa, pp. 693-706.

Roth, A. (2013). Testing and Numerical Modeling of High-tensile Steel Wire Mesh for Ground Support under Dynamic Loading, MSc thesis, Western Australian School of Mines, Curtin University, pp. 24-64.

Saner, A., and Murri, R. (2016). Testing of the Rockburst Codelco Setup S3-S5, Report No. Psi-16-1231, DTC, Vauffelin/ Biel, Switzerland.

Thompson, A., Player, J. and Villaescusa, E. (2004). Simulation and analysis of dynamically loaded reinforcement systems, Ground Support Symposium, Perth, Australia, pp. 341-355.

Villaescusa, E., Azua, J.M., Player, J.R., Thompson, A.G. and Morton, E. (2012). A database of static and dynamic energy absorption of mesh for rock support, CRC Mining, Western Australian School of Mines, Curtin University, pp. 1-8. 